presentations of abstracts of original research.

\section{ABSTRACT AND MEETING INFORMATION}

Abstracts for the Conference on Prevention of Transmission of Bloodborne Pathogens in Surgery and Obstetrics should be typed on plain white paper, single spaced, no longer than 250 words, with two-inch top and bottom margins and 2 1/8-inch side margins. The abstract should be headed with title, author names with degrees and institutions, city and state, with an asterisk next to the presenting author. This is to be followed by the objectives, methods, results, and conclusions of the research. Abstracts will be printed exactly as received.

Mail abstract and four copies, with presenting author's address and telephone number, to Bloodborne Pathogen Conference, HIV
Infections Branch, Hospital Infections Program, Centers for Disease Control and Prevention, Mailstop A-07, Atlanta, GA 30333. Deadline for receipt of abstracts is October 31, 1993.

For hotel information and registration forms, contact Mr. John P.Lynch, Organization Department, American College of Surgeons, 55 East Erie Street, Chicago, IL 60011-2797. Telephone (312) 664-4050.

\title{
Advisory Committee on Immunization Practices (ACIP) Recommendations for the Immunization of Healthcare Workers
}

Current recommendations on the immunoprophylaxis of healthcare workers can be found scattered in existing published ACIP Statements. These recommendations will be consolidated and updated in an upcoming ACIP publication. In this new publication, the vaccine-preventable diseases will be arranged in categories ranging from diseases against which all health workers should be immunized, such as hepatitis B and influenza, to those that would require vaccination only in select settings.

The new publication also will address the value of BacilleCalmette-Guerin (BCG) in the prevention of tuberculosis and the problem of immunizing immunocompromised healthcare workers. The designation "healthcare worker" in this document will apply broadly to include workers in private doctors' offices, nursing homes, schools, laboratories, and first response teams.

Raymond A. Strikas, MD, of the Division of Immunization, Centers for Disease Control and Prevention, anticipates a fall publication date in the Morbidity and Mortality Weekly Report (MMWR).

\section{Training Course in Hospital Epidemiology}

The Society for Hospital Epidemiology of America (SHEA), with the Centers for Disease Control and Prevention (CDC) and the American Hospital Association (AHA), will cosponsor another training course for hospital epidemiologists.

The course is scheduled for September 12-14, 1993, in Seattle, Washington, and is being organized and taught by representatives from some of the most influential organizations in this country to deal with infection control.

The course is intended for infectious diseases fellows and new hospital epidemiologists, and will emphasize hands-on exercises in which participants work in small groups to detect, investigate, and control epidemiologic problems encountered in the hospital setting. These working sessions will be supplemented with lectures and seminars covering fundamental aspects of hospital epidemiology.

Course information is available from Ian Dockrill, SHEA Meetings Department, 875 Kings Highway, Suite ZOO, Woodbury, NJ 08096 3172. Telephone (609) 845-1720; fax (609) 853-0411.

Brief items of interest for the SHEA News or Newsletter may be sent to C. Glen Mayhall, MD, SHEA, New sletter Editor, Division of Infectious Diseases, Department of Medicine, University of Tennessee, Memphis, 956 Court Ave., Memphis, TN 38163; FAX (901) 528-5854. Copy should be typed, double-spaced, and should not exceed five pages. 